\title{
Rasgos fundamentales de la Filosofía Contemporánea.
}

La Filosofía actual, no sólo se distingue por el enorme acopio de su producción, que hace de nuestra época, tua de las mús ilustres de la historia del pensamiento, sino también porque a pesar de la multiplicidad de los pensadores y de los sistemas posee caracteres tiniformes que la diferencian de todas las épocas anteriores.

A primera vista ptidicra parecer nuestra aserción, arbitraria y hasta dogmática. Pero si se analiza debidanente las principales cortientes decia época y las investigaciones más significativas, se ve con evidencia que no se pueden reducir a meros agregados, productos de la sóla iniciativa individual, sino que corresponden a ciertas tendencias genenerales, caracteristicas de nuestro tiempo. $Y$ esto puede verse sobre todo, si no se considera a las diversas producciones filosóficas, según los autores o los países o las escuelas, sino segin los problemas ante los ctiales se enfrentan. Una producción fillosófica no se puede comprender sino según el problema que trata de resolver o en último caso, de precisar. Y es esta tal vez. la razón, por la que la mayor parte de tas historias de la Filosofía, clan tuna erradísina visión de las épocas diversas del pensar humano, porque no abordan 
las grandes producciones filosóficas, descle el punto de vista problemático - único que permite captar su sentido y su ubicación dentro de la cultura humana - sino descle vulgares puntos de vista de escuela y hasta de nacionalidad. Esto ha pasado sobre todo con la Fílosofía contemporánea que por propia naturaleza es la que menos se presta a clasificaciones artificiales y forzadas. Por eso, casi todos aquellos que han tratado de obtener una visiun de conjunto sobre ella, a través de historias de la Filosofía y de textos muiversitarios, han créido que el pensar contemporineo es una ahigarrada colección de producciones sin dirección de ninguna clasé, en la que prima la habilidad personal y el "virtuosismo" filosófico. Nada más errédo que esta crecncia.

La Filosofía contemporánea, ẹs verdad, presenta una serie de escuelas, y una gran multiplicidad de pensadores. Es además una Filosofia en la que el genio personal y el virtuosismo han brillado con mayor intensidad que nunca. Pero en su esencia está orientada hacia el tratamiento de una genuina problemática, gue comparada con las anteriores sobresale por su autenticidad filosófica, por su originalidad y por su alto significado humann. Tres son los grandes problemas que dan sentido y uniformiclad a la Filosofia contemporánea y que han hecho que sea tal vez la más interesante de todas las filosofias: el problena del conocinjiento, el problema del espíritu y el problema del ser. Es pues, descle este punto de vista que vanos a abordar el pensar contenporáneo.

De todos estos problemas el primero que se plantearon los pensadores actuales fué el del conociniento. El estudio del conocimiento es por esta razón lo primero que bay que considerar para comprender el sentido intimo del presente pensamiento filosófico. $Y$ además hay que tener en cuenta 
que todos los dcmás problemas hacia los cuales está orientado, han sido entrevistos y planteados, gracias al problema del conocimiento. De manera que en el fondo, tanto el prohlema del espíritu comio el dei ser, estái determinados a travis del problema del conocimiento y todas las ramas de la Filosofía actual están teñidas con su resplandor. La Filosofía contemporánea es una Filosofía eminentemente noseológica.

El problema noscológico, aunque planteado ya por Descartes, y desarrollado por Locke, sólo adquicre relieves precisos con Kant. Tres son sus caracteres esenciales: la determinación de los límites del conocimicnto en general (el aspecto cminentemente crítico del problema) la explicación de la objetividad, el estudio del apriori.

Con esta triple finalidad, que se puede reconocer con facilidad en la enmarañada selva de la "Crítica cle la Razón pura" Kant abre el camino a la gloriosa tradición crítica, Estos tres puntos son los que han dado la pauta a investigaciones posteriores, sin que csto quiera decir que no se hayan considerado nuevos puntos.

Después de Kant surgen una serie de escuelas, cada una de las cuales trata de ampliar y de perfeccionar la obra del maestro. Pero estas escuelas sólo se constituyen después de algunos años de maduración, pues la obra de Kant, no fué comprendicla apenas vió la luz. El romanticismo alemán forma una especie de interregno. Fichte, Schelling, y Hegel aunque en su Filosofía se nota una enorme influencia kantiana, pertenecen sin embargo a una época anterior a Kant. Se sirvieron constantemente de las eseñanzas del maestro sin comprenderlo. Esto no es una negación de su genio personal. Hegel sobre todo, aunque no logró jamás posesionarse del espíritu crítico que debe caracterizar a todo teórico 
del conocimiento, realizó descubrimientos fundamentales en lo referente a la Filosofía del espíritu como veremos más adelante.

La primera escuela poderosa, que proviene directamente de Kant, es el positivismo. Los positivistas parten sobre todo de la negación que Kant hace de la posibilidad de la Metafísica. Además, como aporte propio sostienen que la esencia del conocimiento es la descripción. Pero la descripción sólo puede hacerse si se tiene conciencia de contenidos concretos e individuales. Surge así, la tan famosa y ya tan criticada doctrina positivista, con todas sus virtudes y sus defectos. Su principal virtud consiste en haber convencido a nuestra civilización actual de que ya no es posible producir filosofías epeculativas. El positivismo ha servido para reforzar y perfeccionar las conclusiones de la "Dialéctica trascendental" de Kant. Sus dos grandes defectos son: el no haber aplicado su propio punto de vista descriptivo, pues si se rescribe la Ciencia debidamente, se ve con plena evidencia que el espíritu de la Ciencia no sólo es descriptivo sino que también es explicativo; y el haber querido simplificar todos los problemas, cayendo con esto en un racionalismo ingenuo. Además como otródefecto secundario puede mencionarse su concepto demasiado estrecho de descripción y de experiencia.

El positivismo-originado únicamente a base de una concepción sobre el conocimiento - tuvo una enorme influencia. Duró en Francia hasta fines del siglo XIX, y en Inglaterra hasta ya entrada la presente centuria. En alemania sólo llega hasta el 1870 en que empieza a surgir el neokantismo, una de las escuelas epistemológicas más importantes de la actual época.

Contraponiéndose al positivismo, el neokantismo insiste en el aspecto explicativo de la Ciencia, y llega hasta la 
exageración de afirmar que la descripción no tiene lugar en el conocimiento científico. Sin embargo a pesar de este radicalismo, y a pesar de haber caído muchas reces en un idealismo que contradecía su posición abiertamente ametafísica, el neokantismo puede considerarse como uno de los movimientos filosóficos más serios de todos los tiempos. Sus análisis sobre el conocimiento científico son de una exactitud y de una penetración sorprendentes. Son los primeros que llesan a un esclarecimiento verdaderamente esencial de lo que significa la objetividad dentro del conocimiento científico. Gracias al neoliantismo la Filosofía actual cuenta con análisis filosóficos de las Ciencias particulares, sobre todo de las naturales, y además ha acentuado enormemente su sentido crítico.

Dentro del neokantismo surgen una serie de sub-escuelas. La principal de ellas es la de Marburgo, que se distingue por su idealismo y por su orientación hacia las Ciencias naturales. Tenemos además a la escuela de Baden orientada hacia las Ciencias culturales. La escuela ficcionalista de Vaihinger tambiénetiene importancia. Uno de los últimos neokantianos notables ha sido Cassirer, que es seguramente el único filósofo que ha logrado dar una interpretación epistemológica brillante de la Teoría de la relatividad de Einstein, demostrando que la importancia de esta teoría es haber logrado una mayor objetividad para los conocimientos físicos.

La reacción contra el radicalismo constructivo de los neoliantianos no se dejó esperar mucho tiempo. El conocimiento no sólo es explicación, mediante la elaboración apriorística de conceptos, es también descripción. Y más aún es auténticamente descripción. Surge así la hoy universalmente conocida corriente fenomenológica. El mérito fundamental de este movimiento es haber ampliado el concepto de des- 
cripción, el de intuición y el de experiencia. Además los fenómenólogos son los primeros que se han dado cuenta del significado esencial de la Conciencia como campo cle investigación filosófica. Por otra parte, con su teoría de la intencionalidad, han renovado la antigua teoría del concepto, y han demostrado la autenticidad del conocimiento esencial. Tienen el defecto sin embargo de haber caído en tesis metafísicas, después de haberlas rechazado por principio. Además han vuelto a cometer el error de los positivistas: el radicalismo de la descripción, aunque de manera menos ingenua y simplista. Y lo que es más, muchos de los análisis que han realizado, y a los cuales dan suma importancia, se basan. más que en verdaderos datos, descriptivamente puros, en hipótesis explicativas.

Paralelamente a la Fenomenología, se ha desarrollado el Neopositivismo, el cual trata de coordenar el verdadero sentido de la crítica kantiana con el positivismo. Desear evitar las ingenuidades del antiguo positivismo, como por: ejm., querer derivarlo todo de la experiencia sensorial. Aceptan la autonomía del conociniento apriori, aunque sólo del apriori analítico. Noseológicamente - fuera clel análisis del conocimiento apriori no tienen gran importancia. Pero lo que les da interés es su contribución al desarrollo de la Lógica simbólica, desarrollo que con algunas excepciones, ha sido producido exclusivamente por dicha escuela.

Después del movimiento fenomenológico, han surgido pensadores independientes, que han tratado de coordenar a la Fenomenología con el Neokantismo. El más importante de ellos es Nicolai Hartmann, que pertenece al movimiento de los realistas críticos. Hay que mencionar también el movimiento realista, que ha tenido lugar tanto en Inglaterra como en Estados Unidos, y que también tiene honda raigam- 
bre noseológica. Su principal interés estriba en corregir los errores del positivismo y del neokantismo, y dentro de una orientación crítica general, llegar a una Teoría del conocimiento, sin radicalismos unilaterales.

En las últimas décadas del siglo pasado, la Teoría del conocimiento logra un desarrollo tan enorme que se extiende de las Ciencias de la Naturaleza, único lugar que se había investigado, a otra clase de Ciencias que unos como Rickert llaman Ciencias culturales, y otros como Dilthey llaman Ciencias espirituales. Los teóricos del conocimiento se dieron cuenta que las leyes específicas que regían el conocimiento de los acontecimientos históricos, y de las grandes proc'ucciones culturales del hombre eran diferentes a las que regían el conocimiento de la naturaleza. Windelband y Rickert descubren que todo conocimiento cultural presupone una selección de valor, y Dilthey demuestra que el conocimiento histórico no puede basarse en explicaciones deductivas sino en comprensiones de situaciones espirituales.

Se ve así, como de una mejor determinación del problema del conocimientó ya surgiendo el problema del espíritu. En efecto, si el conocimiento de todo aquello que tiene que ver con la cultura y con la Historia es distintito del conocimiento orientado hacia la naturaleza, es porque el objeto de la intención cognoscitiva debe tener caracteres especiales. $Y$ seguramente la estructura de estos caracteres es la que imponen al conocimiento formas específicas. Estudiando pues esta realidad habrá de comprenderse, el porqué de aquella especificidad cognoscitiva. Empieza de esta manera el estudio del espíritu. Al principio de manera vaga, casi secundaria. con Rickert y con Dilthey. Luego Bergson, en su genial crítica a la sicofísica y a la Noseología positivista, realiza magníficos logros en la teoría del espiritu. Hasta que por último se estudia el tema por sí mismo, y el espíritu como realidad 
humana se trasforma en un importante tema de la investigación filosófica actual.

Debiclo a que el problema se precisó a través de la T’eoría del conocimiento, el actual estudio del espiritu no tiene nada de metafisico ni de especulativo. Por espíritu no se debe entender aquel concepto atávico que tuvicron los medioevales. El espíritu críticamente considerado, es sencillamente aquella "realidad" que exige del conociniento formas especiales para ser captaclo. Es aquella realidad que sólo pue.cle comprenderse y no explicarse. El espíritu no es una sustancia inmortal que se halla "encerrado" en el cuerno. Tis sencillamente una manifestación de lo real con caractcres propios, y que exige actos cognoscitivos especiales.

Esto es lo tute brillantenrente establece Spranger en su obra "Formas de vida". Demuestra la existencia de 111 apriori sintético con modalidades propias, para el conocimiento de lo espiritual y estudia la naturaleza de la referencia de la personaliclad a los valores, referencia que constituye la esencia de la espiritualidad.

Max Scheler, entsucobrac"Eeptiesto del hombre en el cosmos" supera las investigaciones de Spranger, demostrando que la referencia al valor es sólo uno de los tantos caracteres de lo espiritual, y lo reduce a un caso particular del trascenderse.

Por último Nicolai Hartmann en su obra "El problema del ser espiritual" completa la investigación haciendo ver como el estudio del espíritu es incompleto si no se toman en r.tenta el "espíritu objetivo" y el "espíritu objetivado". El concepto de "espíritu objetivo" según el mismo Hartmann fué descubierto por vez primera por Hegel. A pesar de los absurdos metafísicos que pululan en todas stus obras, Hegel tuvo intticiones geniales. Una de estas ha sido la del espiritu objetivo, es decir la del espiritu supraindividul, concep- 
to que despojado de su abstruso ropaje metafísico es uno c.e los formidables pilares de la nueva tecría del esp!ritu.

La esencia del espíritu objetivo según Hartmann estriba en la "desligabilidad de los contenidos de conciencia", es decir en la posibilidad de que estos tienen de pasar de una conciencia a otra y de ser posesión común de un gran número de conciencias.

El concepto del espíritu objetivo es en último término el más importante en la teoría del espíritu, porque el espíritu personal, no se puede comprender esencialmente si no se le ubica dentro del espíritu objetivo, que es el que le brinda la base para su propio desarrollo.

El espíritu objetivado es la fijación cle contenidos de conciencia ( $y$ por lo tanto de contenidos espirituales) en objetos no espirituales, y constituye la base de la investigación histórica. Es también de suma importancia para la teoría general del espíritu.

Despućs de esta obra fundamental la doctrina del espíritu ha entrado en un período de sistematización, similar al de cualquier rama de la intestigación filosófica. Su problemática se ha precisado y sucampo se ha evidenciado como uno de los más fructíferos del temario filosófico.

Pero el problema del espíritu no es el único que se ha clerivado del problema del conocimiento. Hay otro problema, aún más importante desde el punto de vista filosófico, que debido al enorme desarrollo de la Teoría del conocimiento, ha podiclo precisarse y abordarse: el problema del Ser.

En este punto sin embargo hay que tener sumo cuidado cle no interpretar inadecuadamente este interesante aspecto de la Filosofía actual, que aunque parezca paradójico, es el más reciente de todos.

Muchos han creíclo que el presente tratamiento del problema del Ser es un retorno a la Metafísica antigua, y que 
las actuales teorías ontológicas no son sino perfeccionamientos de la doctrina aristotélico-tomista. Nada más erróneo que este punto de vista. La Metafísica actual no es un "retorno", es una "llegada". La investigación no ha regresado sobre sus pasos. Ha seguido en línea ascendente, descle que Kant rompió el fuego con la "Crítica de la Razón pura". La vía que ha seguido, se ha presentado llena de alternativas $y$ de desniveles. Pero siempre ha permanecido dirigida hacia adelante. Y avanzando sobre ella, los filósofos han llegado a una región a la que jamás pensaron llegar: la región del Ser. $Y$ una vez allí siguieron animosamente hasta llegar a contemplar uno de los panoramas más sorprendentes en toda la historia del pensamiento.

La vía a través de la cual los actuales filósofos han llegado al Ser, ha sido la Teoría del conocimiento; Kant, los positivistas, los neokantianos, los fenomenólogos, son las cuatro etapas del camino. Esto parece a primera vista imposible. La crítica del conocimiento, siempre ha negado a la Metafísica. Si, pero la ha negado por los resultados, no por la esencia del problema que se plantea. El problema fundamental de la crítica del conocimiento es la extensión del conocimiento. De manera que una de las preguntas fundamentales de toda Noseología es: ¿ ¿se puede conocer el Ser? Si se considera este aspecto de la Teoría del conocimiento, se ve que es no contraria a la Metafísica sino indiferente hacia ella. Ni la niega ni la afirma. Sólo pregunta por su posibilidlad.

Pues bien al principio, la respuesta a la pregunta, fuć negativa. Pero poco a poco, la Noseología se fué desarrollando, fué cambiando, pudo disponer de nuevos elementos, $y$ hoy la respuesta es positiva.

Por supuesto que la positividad de la respuesta se halla encuadrada dentro de múltiples restricciones críticas. Na- 
da de dogmatismos, nada de apriorismos especulativos. Aunque para un ontologista clásico, esta afirmación podría sonarle como tuna blasfemia, hoy se hace Ontología a posteriori.

A cattsa del origen noseológico, del problema ontológico actualmente considerado, la actual Metafísica es, como ha de suponerse, completamente distinta a la clásica. Debido a la falta de espacio y de tiempo, sólo enunciaremos algunas de sus diferencias más importantes.

En primer lugar la Metafísica presente ya no es racionalista. Esta es una de las adquisiciones más formidables del pensar contemporáneo. Los griegos y los medioevales creyeron que las categorías de la razón coincidian por completo con las categorías del Ser. Y por esa causa construyeron una Metafísica racionalista. Creyeron que bastaba que una cosa fuera lógica y racional para que tuviera existencia ontológica. Por eso llegaron a construir sistemas de maravillosa armonía, pero que no tenía nada que ver con el Ser. $Y$ fueron destruídos por la crítica de la manera más crttel y aplastante.

La Metafísica actuab acepta sólo una coincidencia parcial entre las categorías de la Razón y las del Ser. Por eso, el Ser es sólo parcialmente sistematizable. Hay un aspecto del Ser, que no sólo no es racional, sino que es irracional ¡Hay contradiciciones ontológicas! Esta es la afirmación más audaz y sin embargo más real que se ha hecho en todos los tiempos. Estas contradicciones sólo pueden describirse, pero no comprenderse, ni mucho menos resolverse.

Otra diferencia fundamental entre las dos Metafísicas, es que la antigua tenía el prejuicio de la unidad, del cual carece por completo la actual. Para los antiguos siempre debía de existir un principio supremo, que era Dios, o la Naturaleza, o la materia, o la vida, etc. La Ontología actual reco- 
noce la pluratidad de los principios. El Ser se divide en tuna serie de estratos, que aunque se relacionan unos con otros son irreductibles. No hay principio supremo. Ia creencia en él es un prejuticio místico-religioso, pero no tuna realidad metafísica.

Otra conquista de la nueva Metafísica es el convencimiento de que la primacía ontológica le corresponde al Ser real y no al ideal. El ser ideal, debido a que es el más fácilmente cognoscible, había recibido desde los tiempos de Platón. una especie de halo místico, y se había considerado como la única región con verdadera consistencia ontológica. Hoy se ha demostrado sin lugar a dudas, que el Ser real, el ser indiviclual y espaciotemporal es tan Ser como el icleal, y aún más, porque es cualitativamente muchísimo mís rico.

La inclusión del tiempo en la problemática Metafísica es también otra de las diferencias dignas de mención. La antiguta Metafísica no lo tomaba en cuenta para nada. Sólo se refería a él, como principio separador cle las esferas del Ser. El Ser real era temporal, el Ser icleal era intemporal. Hoy se ha descubierto que el tiempo no se puede reducir a mero principio separador. Es demasiado mportante para ello. La esencia del Ser no se puede comprender sin un adentramiento en la esencia de la temporalidad. Desde luego, hay algumas escuelas que profesan un radicalismo de la temporalidad, y creen que la Ontología se reduce a un estudio de ella.

Este punto de vista es exageraclo. Pero esto no quiere decir que el tiempo no tenga importancia fundamental para todo sistema ontológico que pretenda efectuar un estudio no espectulativo del Ser.

No cabe duda que a pesar de estas diferencias, que crean un abismo entre las dos Metáfísicas, ambas, la antigua y la nueva pretenden estudiar el Ser. Además muchas de las ad- 
quisiones de la antigua Ontologia aristotélica-tomista, han sido reconocidas como válidas por la Ontología actual. Pero de todas maneras no puede hablarse de un retorno. El siguiente simil hará comprender que clase de relación existe entre ambas Metafísicas. Cuando no se sabia que el mundo era redonclo, hubo un grupo de hombres que salió de un lugar de la tierra, y avanzando, siempre avanzando, a través de una vía llena de alternativas, llegó al punto de partida.

¿Se puede decir que regresaron a su base? ¡No! Regresar hubiera sido volver por el mismo camino. En cambio para ellos el camino siempre fué variado y regocijaron sus ojos con el sabor de lo nuevo. Y fué nuevo para ellos aún el lugar del que partieron, porque después de haberse convencido de que la tierra era redonda ya no podían verlo con los mismos ojos.

Asi ha pasado con la Metafísica. Se ha llegado al Ser. $\mathrm{Y}$ este Ser es evidentemente el mismo Ser que conocieron los antiguos. Pero se ha llegado por caminos completamente nuevos, completanientecinsospechadōs para la antigüedad. Y este camino ha sido la vía de la Noseología Por eso la visión que hoy tenemos del Ser, es mas amplia, más segura, más libre.

$\mathrm{Y}$ en él fondo, gracias a la orientación fundamental de la Filosofía contemporánea hacia el problema del conocimiento, todos sus logros y todas sus conquistas son como la nueva Ontologia: más amplias, más seguras, más libres.

Se ve pués, como enfocada problemáticamente, la Filosofía actual, no se revela cual una colección abigarrada de pensamientos individuales, sino como un progreso constante y unitario, y cómo todos sus temas se hallan orgánicamente engarzados dentro de una orientación común. Desde 
el punto de vista de los problemas, no seria demasiado arriesgado a firmar, que la Filosofia contemporánea es tal vez la más unitaria de todas las filosofias.

Francisco Miró Quesada.

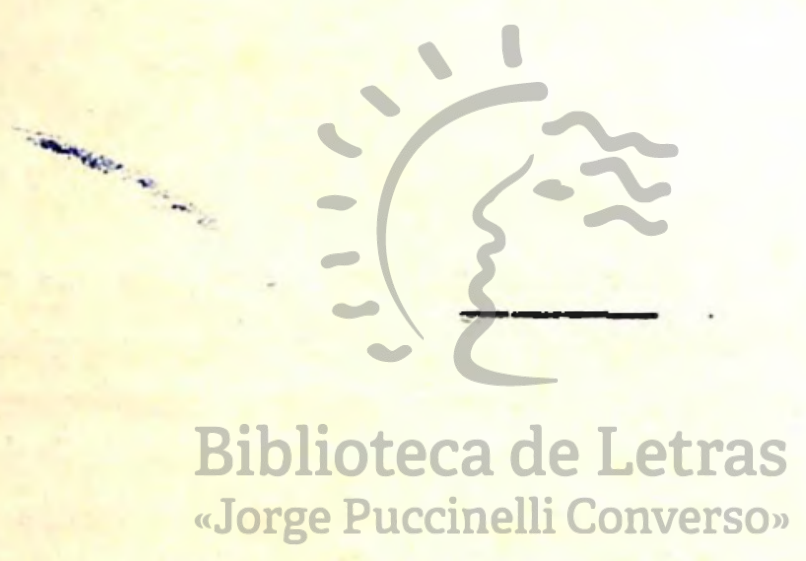

